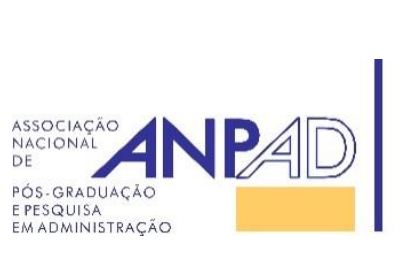

Disponível em

http://www.anpad.org.br/rac

RAC, Rio de Janeiro, v. 20, n. 1, art. 1,

pp. 1-20, Jan./Fev. 2016

http://dx.doi.org/10.1590/1982-7849rac2016140036

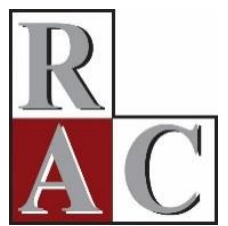

(c) $\mathrm{EY}$

\title{
Capacidade de Absorção, Aprendizagem Organizacional e Mecanismos de Integração Social
}

Absorptive Capacity, Organization Learning and Social Integration Mechanisms

Florindo Rhaoni Picoli ${ }^{1}$ Adriana Takahashi ${ }^{1}$

Universidade Federal do Paraná ${ }^{1}$

Artigo recebido em 05.09.2014. Última versão recebida em 26.01.2015. Aprovado em 21.05.2015. 


\title{
Resumo
}

O objetivo deste artigo é buscar compreender de que maneira se dá o processo recursivo de capacidade de absorção e de aprendizagem organizacional, por meio de mecanismos de integração social, na utilização do Programa Paraná Digital em duas instituições de ensino público de Curitiba - Paraná, no período de 2007 a 2013. Os procedimentos metodológicos pautaram-se em uma pesquisa exploratório-descritiva, de abordagem qualitativa, realizada por meio da estratégia de estudo de caso comparativo, com uma perspectiva temporal de corte transversal. A coleta de dados ocorreu por meio de entrevistas, pesquisa documental e observação não participante. A análise de conteúdo foi a técnica utilizada para compreender os dados obtidos. Verificou-se que a completude do processo de capacidade de absorção leva à plena aprendizagem organizacional, e que as falhas em um processo impactam o outro, demonstrando a recursividade, que é mediada por mecanismos de integração social.

Palavras-chave: capacidade de absorção; aprendizagem organizacional; mecanismos de integração social.

\begin{abstract}
The purpose of this paper is to seek to understand how the recursive process related to organizational capacity for absorption and learning occurs through social integration mechanisms, as exemplified in the implementation of the Paraná Digital Program in two public education institutions in Curitiba, Paraná, during the period from 2007 to 2013. The methodology used was qualitative, exploratory, and descriptive, accomplished by means of a comparative case strategy with a temporal cross-sectional perspective. Data collection was accomplished through interviews, document analysis and participant observation. Content analysis was used to comprehend the data obtained. Results show that a completed absorption capacity process leads to full organizational learning, and that faults in one process impact the other, demonstrating a recursive relationship mediated by social integration mechanisms.
\end{abstract}

Key words: absorption capacity; organizational learning; social integration mechanisms. 


\section{Introdução}

O ambiente dinâmico no qual as organizações atuam levam-nas à permanente necessidade de se adaptar e desenvolver melhorias em seus processos, permitindo-lhes sobreviver e evoluir diante das demais (Lichtenthaler, 2009). Para tanto, elas precisam estar atentas à identificação de oportunidades e captura de conhecimento externo, que atua como elemento gerador de inteligência ao viabilizar a adaptação e otimização das atividades realizadas no contexto organizacional (Liao, Welsch, \& Stoica, 2003).

A criação de valor e o progresso das operações internas, a partir do conhecimento, estão atreladas à capacidade de absorção, tida como a habilidade de cada organização em adquirir, assimilar, transformar e explorar da melhor maneira possível conhecimentos novos e externos (Jansen, Van den Bosch, \& Volberda, 2005).

A capacidade de absorção constitui-se, segundo Lane, Koka e Pathak (2006), como elemento essencial para o sucesso de uma organização, visto que reforça, complementa e transforma aquilo que ela já sabe, possibilitando internalizar e utilizar novos conhecimentos por meio de processos de aprendizagem. A aprendizagem organizacional, para Fiol e Lyles (1985), está intimamente ligada à mudança, adaptação e ajuste da organização, como forma de responder e agir a partir da interpretação de eventos e associação cognitiva realizada pelos membros organizacionais. Ademais, Versiani e Fischer (2008) destacam que para haver o aprendizado organizacional, é necessário que haja a incorporação ou desenvolvimento de conhecimentos, tratando-se, portanto, de um processo que ocorre de maneira fluida. O fluxo de conhecimento é, assim, o elemento chave tanto da aprendizagem organizacional quanto da capacidade de absorção. Isso gera uma interface recursiva entre ambos os conceitos.

Deve-se destacar, ainda, que o conhecimento, enquanto aspecto central da capacidade de absorção e aprendizagem organizacional, não é absorvido de forma igual entre as organizações, pois sua internalização difere em cada uma delas (Hotho, Becker-Ritterspach, \& Saka-Helmhout, 2012). Tal diferenciação está atrelada à forma como as informações são compartilhadas no ambiente organizacional, tendo em vista que as pessoas interagem e dividem experiências de maneira diversa por meio de mecanismos de integração social que atuam como elementos auxiliadores da absorção informacional (Zahra \& George, 2002).

Organizações com características similares, presentes no mesmo ambiente e expostas aos mesmos conteúdos, possuem distinções nos mecanismos de integração social, processos de aprendizagem e absorção de conhecimento, o que consequentemente leva à diferença de performance. Ou seja, as organizações são compostas por diferentes características internas que irão interferir na forma como ocorre a interação interpessoal e o fluxo de informações, tornando a absorção de conhecimento particularizada e levando a resultados organizacionais específicos (Vega-Jurado, Gutiérrez-Gracia, \& Fernández-de-Lucio, 2008).

Com base nessa conjuntura, considerou-se relevante buscar compreender de que maneira se dá o processo recursivo de capacidade de absorção e de aprendizagem organizacional por meio de mecanismos de integração social. Para isso, investigou-se esta problematização em duas instituições de ensino público de Curitiba - Paraná, levando em conta a implantação, em ambas, de um programa governamental de disponibilização de tecnologias para fins pedagógicos chamado Paraná Digital (PRD). A partir desse objetivo, realizou-se o estudo presente neste artigo, que se divide em quatro seções, apresentadas na sequência. 


\section{Capacidade de Absorção: Conceitos, Dimensões e Características}

O conceito de capacidade de absorção foi originalmente delineado por Cohen e Levinthal (1990), que a definiram como "a habilidade em reconhecer o valor de novas informações externas, assimilá-las e aplicá-las para fins comerciais" (p. 128). Para os autores, a habilidade em valorar conhecimentos de ordem externa está atrelada à base de conhecimento que a empresa possui, pois, ao utilizar aquilo que já conhece a organização, pode delinear os elementos que deve captar externamente para aprimorar os processos por ela realizados.

A incorporação do conhecimento externo nas atividades internas da empresa a partir do prévio reconhecimento de sua validade e relevância também foi tratada por Zahra e George (2002) que, pautando-se no conceito inicial de capacidade de absorção, propuseram uma conceituação calcada em dimensões alocadas em dois grupos complementares: o de capacidade de absorção potencial e o de capacidade de absorção realizada. Conceituaram-na, portanto, como "um conjunto de rotinas organizacionais e processos pelos quais a empresa adquire, assimila, transforma e explora o conhecimento com o propósito de criar valor" (Zahra \& George, 2002, p. 186). Visualizaram-na como uma capacidade dinâmica embutida nas práticas organizacionais, que por meio de suas quatro dimensões, separadas em um grupo de potencialidade e outro de realização, viabilizam a criação de vantagem competitiva.

A capacidade de absorção do grupo potencialidade engloba, segundo Zahra e George (2002), a dimensão de aquisição e assimilação, de forma que a primeira se refere à capacidade da organização de identificar e adquirir o conhecimento externo considerado relevante e essencial à realização das suas operações, ao passo que a segunda é pontuada como processo de análise, interpretação e entendimento das informações obtidas externamente, pois somente por meio da efetiva compreensão se torna possível assimilar e internalizar algo novo. A aquisição e assimilação são consideradas dimensões potenciais por se restringirem a um caráter analítico do conhecimento externo, sem que sua incorporação tenha sido efetuada.

Compete à capacidade de absorção do grupo de realização o processo de incorporar o conhecimento obtido e compreendido na etapa potencial, fazendo com que as operações organizacionais se modifiquem por meio da junção entre as novas informações e as experiências já existentes. Isso ocorre com base, primeiramente, na dimensão de transformação, que enfoca a habilidade de combinar o conhecimento existente com o novo, avaliando suas semelhanças e diferenças a fim de gerar modificações que permitam desenvolver e refinar rotinas. Posteriormente, por meio da exploração, esse refinamento das ideias e atividades organizacionais deve ser capaz de estender ou criar novas competências que possam ser utilizadas para gerar bens, sistemas e processos pela incorporação e aplicação do conhecimento adquirido, assimilado e transformado (Zahra \& George, 2002).

Estudos empíricos avançaram no direcionamento de validação do conceito e dimensões propostas por Zahra e George (2002). Dentre eles destacam-se as pesquisas realizadas por Jansen, Van den Bosch e Volberda (2005), Camisón e Fóres (2010) e Jiménez-Barrionuevo, García-Morales e Molina (2011). Esses últimos autores caracterizaram cada uma das dimensões da capacidade de absorção, conforme descrito na Tabela 1. 
Tabela 1

\section{Dimensões da Capacidade de Absorção}

\begin{tabular}{|c|c|c|}
\hline Dimensão & Componente & Definição \\
\hline \multirow[t]{2}{*}{$\begin{array}{l}\text { Capacidade } \\
\text { de Absorção } \\
\text { Potencial }\end{array}$} & Aquisição & $\begin{array}{l}\text { É a capacidade da organização em localizar, identificar, avaliar e adquirir } \\
\text { conhecimento externo considerado importante para o desenvolvimento de } \\
\text { suas operações. }\end{array}$ \\
\hline & Assimilação & $\begin{array}{l}\text { É a capacidade da organização em compreender o conhecimento (ou } \\
\text { informação) advindo de fora da empresa. Trata-se, portanto, da habilidade } \\
\text { em analisar, classificar, processar, interpretar e, ultimamente, internalizar e } \\
\text { entender o conhecimento. }\end{array}$ \\
\hline \multirow[t]{2}{*}{$\begin{array}{l}\text { Capacidade } \\
\text { de Absorção } \\
\text { Realizada }\end{array}$} & Transformação & $\begin{array}{l}\text { É a capacidade da organização em facilitar o compartilhamento e } \\
\text { combinação do seu conhecimento anterior com o novo conhecimento } \\
\text { adquirido e assimilado. Consiste em adicionar ou eliminar conhecimento, } \\
\text { interpretar e combinar o conhecimento existente de uma nova e diferente } \\
\text { maneira. }\end{array}$ \\
\hline & Exploração & $\begin{array}{l}\text { É a capacidade da empresa em incorporar o conhecimento adquirido, } \\
\text { assimilado e transformado em suas operações e rotinas para a aplicação e } \\
\text { uso organizacional. Esta capacidade dará origem à criação ou melhoria de } \\
\text { um bem, sistemas, processos, formas organizacionais e competências. }\end{array}$ \\
\hline
\end{tabular}

Nota. Fonte: Adaptado de Jiménez-Barrionuevo, M. M., García-Morales, V. J., \& Molina, L. M. (2011). Validation of an instrument to measure absorptive capacity. Technovation, 31(5/6), 190-202. doi: 10.1016/j.technovation.2010.12.002

\section{A relação com a aprendizagem organizacional}

Chauvet (2014) considera que o estudo da capacidade de absorção por meio de suas quatro dimensões possibilita enxergar a contribuição e relação de cada uma com o processo de aprendizagem organizacional.

Cohen e Levinthal (1990) destacam que a capacidade de absorção não depende somente da interface organizacional com o ambiente externo, mas principalmente do compartilhamento de conhecimento dentro das unidades organizacionais. Inter-relaciona-se, portanto, com o processo de aprendizagem, no qual os indivíduos terão que utilizar o que já sabem para assimilar novas informações, compreendendo-as e agindo com base nas mesmas para transformar as suas práticas.

A partir das considerações de Cohen e Levinthal (1990), demais pesquisadores passaram a discutir sobre a capacidade de absorção com enfoque na habilidade necessária para partilhar e modificar o conhecimento existente dentro da organização (Mowery \& Oxley, 1995), com base na capacidade de aprender e resolver problemas utilizando a experiência acumulada (Kim, 1998). Os autores ressaltaram a importância da aplicação interna das propriedades obtidas externamente, muito mais do que o simples reconhecimento da existência de valor externo, como também destacaram Lane e Lubatkin (1998).

Volberda, Foss e Lyles (2010) pontuam que os processos internos de aprendizagem e o papel dos indivíduos não podem ser negligenciados durante os estudos acerca da capacidade de absorção, merecendo, portanto, destaque nas pesquisas. Para Lane et al. (2006), é preciso compreender o processo no qual o cerne são as pessoas, pois o que gera vantagem competitiva e/ou melhores resultados é a maneira como os membros da organização aprendem, combinam e aplicam o conhecimento.

O aprendizado exerce, portanto, um papel fundamental para que o conhecimento seja absorvido e utilizado nas organizações, o que leva a considerar a pertinência da conceituação de Takahashi (2007), que parece estar alinhada com o conceito de capacidade de absorção, pois destaca a relevância do fluxo de conhecimento para o processo de aprendizagem organizacional, que ocorre por meio da criação, utilização e institucionalização do conhecimento. Patriotta (2003) descreve como criação o ato de fazer, 
inventar ou produzir o conhecimento, que é incipiente, contestado, controverso e provisório, mas que representa o potencial para produção de conteúdo durável. A utilização consiste na aplicação de um determinado conjunto de conhecimentos em situações concretas, sendo, portanto, constantemente manipulado e transformado, levando a outros processos de criação. A institucionalização faz com que o conhecimento seja incorporado em dispositivos organizacionais estáticos, permanecendo inscrito dentro de estruturas de significação a partir da aceitação dos atores sociais, legitimação e difusão no nível corporativo. Isso entra em consonância com a definição de capacidade de absorção de Zahra e George (2002), visto que também enfoca a ideia de que o conhecimento construído, de maneira fluida por meio do aprendizado, pode se tornar organizacional.

Para Lane e Lubatkin (1998), a relação existente entre a capacidade de absorção e a aprendizagem organizacional é de recursividade, ou seja, à medida que uma organização desenvolve seu aprendizado, ela aumenta sua capacidade de compreender e obter novos conhecimentos, expandindo ainda mais o que ela sabe e ampliando sua aprendizagem. Os elementos relativos à aprendizagem entre organizações, atrelados a sua capacidade de absorção, também são verificados em estudos realizados por Dyer e Singh (1998), Dhanaraj, Lyles, Steensma e Tihanyi (2004), Schildt, Keil e Maula (2012) e Dong e Yang (2015). A recursividade existente entre a capacidade de absorção e a aprendizagem organizacional é defendida, ainda, por Van den Bosch, Volberda e Boer (1999), Autio, Sapienza e Almeida (2000), Tsai (2001), Lane et al. (2006), Hotho, Becker-Ritterspach e Saka-Helmhout (2012), além de Cohen e Levinthal (1990) em seu artigo clássico.

\section{A mediação dos mecanismos de integração social}

Ao expandirem o conceito de Cohen e Levinthal (1990) e elaborar seu constructo, Zahra e George (2002) deram especial atenção à integração social que se faz necessária para que haja efetiva capacidade de absorção organizacional. Os autores inferiram que a capacidade de absorção potencial só se torna realizada quando é mediada por mecanismos de integração social, que se constituem como elo que possibilita que a empresa assimile, transforme e explore o conhecimento.

Além dos mecanismos de integração social que atuam como conectores, Zahra e George (2002) também destacam o papel dos desencadeamentos de ativação, que são considerados como eventos que levam a organização a responder a algum tipo de estímulo, de ordem interna ou externa, levando-a a buscar ou adquirir algo específico e relevante, como uma nova tecnologia, por exemplo, que desencadeará o processo de capacidade de absorção como um todo. Os desencadeamentos internos podem ser ativados por crises, falhas de performance, ou um refinamento estratégico, ao passo que os desencadeamentos com base em fatores externos podem ocorrer devido a inovações radicais, mudanças tecnológicas, ou, ainda, por causa de mudanças em políticas governamentais.

Vega-Jurado, Gutiérrez-Gracia e Fernández-de-Lucio (2008), a partir da concepção e considerações de Zahra e George (2002), consideram que os mecanismos de integração social podem ser definidos como práticas que reduzem as barreiras de troca de informação dentro da organização. Tais práticas constituem-se como atividades formais ou informais, dependendo do grau de sistematização. Ou seja, as atividades formais são instituídas pela organização por meio de procedimentos e normas que as regularizam, como por exemplo, programas de capacitação, adoção de sistemas destinados ao compartilhamento informacional, rotação de trabalho entre funcionários, ou estabelecimento de qualquer ação conjunta formalmente delineada. As atividades informais, por sua vez, acontecem sem que estejam regulamentadas ou tenham a obrigatoriedade de ocorrer, mas podem auxiliar os indivíduos no melhoramento das ações organizacionais.

Camisón e Fóres (2011) também destacam que a existência de interação entre os indivíduos desempenha um papel importante no compartilhamento de conhecimento. Isso faz com que a capacidade de absorção seja específica a cada organização, visto que, embora muitas delas operem em um mesmo ambiente, em um mesmo período de tempo e sob as mesmas condições, incluindo-se a possibilidade de aquisições informacionais e tecnológicas, elas podem, ao fim, ter diferentes níveis de competências, operações e performances. 
Em uma pesquisa destinada a identificar o papel da interação social na capacidade de absorção de distintas subsidiárias de uma indústria química de tintas, Hotho et al. (2012) demonstram que a integração entre as pessoas, a aceitação e envolvimento na adoção de novos procedimentos propiciam a extensiva transformação e aplicação sustentada de um novo conhecimento. A partir da análise desses casos, os autores inferiram que a capacidade de absorção sustentável está atrelada à integração entre os funcionários, sinalizando a afinidade e relação entre esses aspectos que englobam, conjuntamente, a aprendizagem organizacional.

\section{Recursividade entre capacidade de absorção e aprendizagem organizacional por meio dos mecanismos de integração social}

A aprendizagem organizacional e a capacidade de absorção foram, originalmente, relacionadas no artigo clássico de Cohen e Levinthal (1990), dando origem a alguns estudos que abarcam ambas as temáticas. Dentre tais estudos, destaca-se o de Zahra e George (2002) que, ao refletirem sobre a capacidade de absorção, definiram-na como "um conjunto de rotinas organizacionais e processos pelos quais a empresa adquire, assimila, transforma e explora o conhecimento" (p. 186). A partir desse conceito e demais reflexões, os autores inferiram que a internalização de um novo conhecimento, de origem externa, ocorre de maneira fluida e processual. Sinalizam, desse modo, a existência de interface entre a capacidade de absorção e a aprendizagem organizacional.

Ao tratar da incorporação de um novo conteúdo no nível organizacional a partir de fluxos de conhecimento, as considerações de Zahra e George (2002) vão ao encontro da definição de aprendizagem organizacional proposta por Takahashi (2007), que a visualiza como um "processo de mudança transformacional, envolvendo os vários níveis (indivíduos, grupos e organização), pelo qual se dá a criação, utilização e institucionalização do conhecimento" (p. 88). Ocorre, portanto, no âmbito coletivo, abrangendo aspectos cognitivos, comportamentais e culturais, considerando fatores como história, hábitos e experiências.

A partir dos conceitos de Zahra e George (2002) e de Takahashi (2007), observa-se que o fluxo de conhecimento está presente em ambos, sendo, portanto, o elemento que possibilita que haja recursividade entre eles. Deve-se destacar, no entanto, que a definição de aprendizagem organizacional engloba demais aspectos como mudanças, hábitos, experiências, fatores comportamentais e cognitivos, entre outros, que a tornam mais ampla e a diferenciam da conceituação de capacidade de absorção. Infere-se, desse modo, que não se trata de conceitos tautológicos, mas sim que se relacionam de modo recursivo, conforme defendido na literatura, ao terem a fluidez processual do conhecimento como mesma base. Assim, a capacidade de absorção pode envolver um processo de aprendizagem em diversos níveis e não necessariamente o nível organizacional. Para que a aprendizagem ocorra em nível organizacional, é necessário que mudanças profundas ocorram atingindo de alguma forma os valores organizacionais, além da institucionalização do conhecimento. Alguns autores definem este tipo de aprendizagem como de circuito duplo (Argyris \& Schon, 1978), de nível superior (Fiol \& Lyles, 1985) e de alto grau ou transformacional (Barr, Stimpert, \& Huff, 1992).

Além de abordar conjuntamente a capacidade de absorção e aprendizagem organizacional, Zahra e George (2002) evidenciaram que o fluxo de conhecimento, representado pelas quatro dimensões que compõem seu conceito (aquisição, assimilação, transformação e exploração), é mediado por mecanismos de integração social, que se destinam a promover a interação entre os membros organizacionais para que as informações fluam de um estágio potencial de utilização até outro no qual são efetivamente utilizadas no aprimoramento das atividades, ou seja, em uma nova forma de realizá-las.

Os mecanismos de integração social, enquanto elo entre a capacidade de absorção potencial e realizada, conforme defendido por Zahra e George (2002), foram discutidos nos trabalhos de Todorova e Durisin (2007), Vega-Jurado et al. (2008), Leal-Rodríguez, Ariza-Montes, Roldán e Leal-Millán (2014) e Patterson e Ambrosini (2015). Os textos reafirmaram que a integração entre os membros organizacionais é fator preponderante para que haja troca de informações, de ideias e de experiências 
destinadas a gerar interpretações conjuntas que possibilitem que o conhecimento seja de fato compreendido e utilizado.

O conceito delineado por Vega-Jurado et al. (2008) estabelece que os mecanismos de integração social se constituem como atividades, formais e informais, que aumentam a absorção de conhecimento por encorajar a interação e troca informacional entre os diferentes membros, facilitando "a distribuição do conhecimento dentro da organização e, ao mesmo tempo, tornando mais fácil a combinação desse conhecimento com as habilidades e experiências existentes" (pp. 396-397). Essa definição está de acordo, portanto, com os conceitos de capacidade de absorção, de Zahra e George (2002), e de aprendizagem organizacional, de Takahashi (2007), tendo em vista que aponta a integração social como elemento mediador da disseminação e incorporação do conhecimento pela organização como um todo.

Dessa forma, tanto a capacidade de absorção (com suas quatro dimensões de aquisição ou introdução, assimilação, transformação e exploração) quanto a aprendizagem organizacional (norteada pela criação, utilização e institucionalização do conhecimento) ocorrem de modo processual e fluido em etapas que podem ser inter-relacionadas. As dimensões de introdução e assimilação, que dão início ao processo de absorvimento de um novo conhecimento, são análogas à fase de criação inerente ao fluxo que origina o processo de aprendizado da organização, pois se pautam na reflexão, discussão e desenvolvimento de conteúdos provisórios e potenciais que ainda serão alvo de modificações. A dimensão de transformação e a fase de utilização, que dão continuidade aos processos, também podem ser visualizadas como paralelas, visto que ambas buscam promover a modificação e expansão do saber inicialmente gerado. Por fim, a dimensão de exploração e a fase de institucionalização, que completam cada um dos fluxos processuais, inter-relacionam-se ao se voltar para a internalização e incorporação do conhecimento na organização, de modo que o mesmo passe a fazer parte do uso cotidiano e contínuo nas operações e rotinas organizacionais (Zahra \& George, 2002), transformando-se, como pontua Patriotta (2003), em procedimentos, padrões e artefatos. Essa relação também é destacada por Sun e Anderson (2010) ao considerarem que a exploração resultante da capacidade de absorção está intimamente ligada à institucionalização, que pode ocorrer em nível organizacional.

A inter-relação entre as etapas permite compreender a recursividade existente entre ambos os conceitos, que é destacada por Lane e Lubatkin (1998) ao afirmarem que o aprendizado gerado pode aumentar a capacidade de a organização absorver algo novo, que uma vez compreendido e incorporado eleva o conhecimento que ela detém, ampliando suas possibilidades de aprendizagem organizacional. É, portanto, neste âmbito que se configura a recursividade entre a capacidade de absorção e a aprendizagem organizacional.

\section{Procedimentos Metodológicos}

Para a realização dessa pesquisa adotou-se uma abordagem exploratório-descritiva de natureza qualitativa. A perspectiva temporal de análise foi transversal (Neuman, 1999), com corte temporal em 2013, ano da coleta de dados, buscando informações pertinentes que compreendessem o período iniciado em 2007. Foi utilizada, para tanto, a estratégia de estudo de caso comparativo entre duas instituições públicas da rede estadual de ensino pertencentes a cidade de Curitiba - Paraná, sendo elas o Colégio Estadual Santo Agostinho e o Colégio Estadual Professora Luiza Ross.

A escolha das instituições é justificada pelo fato de que ambas passaram pelo processo de implantação de laboratórios de informática destinados ao uso pedagógico de Tecnologias da Informação e Comunicação (TICs) por meio do programa intitulado Paraná Digital, que começou a ser implantado no ano de 2007, pelo governo do Estado, nas escolas públicas estaduais. Os computadores disponibilizados nos colégios, através deste programa, têm como base a utilização de sistema operacional calcado em softwares livres (Secretaria de Estado da Educação [SEED], 2010). 
A decisão quanto à seleção dos colégios pautou-se, primeiramente, no fato de que ambos pertencem à regional curitibana do Programa Paraná Digital que, dentre 32, possui maior índice de número de horas de utilização, conforme dados divulgados no Portal da Educação do Governo do Estado. Ademais, os colégios escolhidos, em meio a todos os que pertencem à mesma regional, possuem características similares quanto a sua localização (mesmo bairro), número de alunos que atendem, número de professores e funcionários, e tamanho do laboratório de informática. Diferem, no entanto, quanto ao número de horas de utilização, visto que um dos colégios possui índices elevados, tornandose um dos que se sobressaem na regional, ao passo que o outro realiza um uso modesto, considerando dados estatísticos do período compreendido entre o início de 2007, quando a implantação ocorreu nas duas instituições, até o fim do ano de 2013 (PRD Estatística, n.d.).

Após a definição das organizações, realizou-se a coleta de dados nas mesmas por meio das técnicas de entrevista, observação não participante e pesquisa documental.

Para participar das entrevistas, foram convidados membros da equipe diretiva e pedagógica, assim como professores e funcionários do setor administrativo que acompanharam o processo de implantação do programa Paraná Digital. O processo iniciou-se, portanto, através da realização de questionamentos com os dirigentes das organizações, que indicaram demais membros que poderiam contribuir com informações relevantes à pesquisa. Estes, por sua vez, também apontaram outras pessoas, valendo-se, assim, da técnica de bola de neve, segundo a qual os primeiros informantes recomendam outros para a entrevista. Dessa forma, realizaram-se entrevistas com 10 membros de cada colégio, totalizando 20 entrevistados, que desempenham as diferentes funções supracitadas e que foram identificados por meio de códigos (E1, E2, E3, e assim sucessivamente até E10, nas duas instituições), a fim de preservar a identidade dos mesmos. Todas as entrevistas foram realizadas dentro das organizações escolares em estudo, utilizando-se um gravador, com o consentimento dos entrevistados, o que gerou 9 horas e 58 minutos de gravação, posteriormente transcrita, possibilitando a análise. Destaca-se que todos os membros convidados a participar da entrevista aceitaram prontamente, não havendo recusas.

No que tange à observação não participante, ela foi efetuada em ambientes como o laboratório de informática, secretaria e sala dos professores, em momentos de trabalho e em horários de descanso, com anotações em um diário de campo, gerando, juntamente com a transcrição das entrevistas, um total de 210 laudas de conteúdos coletados. Quanto à pesquisa documental, ela foi realizada com base no Regimento Escolar, Projeto Político Pedagógico, avisos e recomendações afixadas em murais, informações dispostas nos sites das escolas selecionadas e no Portal da Educação do Governo do Estado. $\mathrm{O}$ uso das três técnicas de pesquisa possibilitou obter diferentes fontes de evidência dos fatos, viabilizando a triangulação, tida por Yin (2010) como elemento base para a validade de estudos de caso.

Findada a coleta de dados, partiu-se para a análise de conteúdo, destinada, conforme pontua Bardin (2010), à descrição, inferência e interpretação das mensagens presentes nas informações obtidas. Dessa forma, o conteúdo foi codificado e analisado com base em dimensões analíticas derivadas da discussão teórica.

\section{Discussão e Análise dos Resultados}

\section{O colégio professora Luiza Ross}

Localizado no bairro boqueirão, em Curitiba - Paraná, o Colégio Estadual Professora Luiza Ross oferta ensino público para cerca de 900 alunos distribuídos nos turnos da manhã e tarde, para o ensino fundamental, e noite, para o ensino médio. Com um número de aproximadamente 80 profissionais, nos quais se incluem professores, pedagogos, diretores e funcionários administrativos e de serviços gerais, o Colégio teve o laboratório de informática implantado no início do ano de 2007, em uma área 74,20 $\mathrm{m}^{2}$, na qual estão dispostos os 20 computadores e demais equipamentos do Programa Paraná Digital. 
A implantação do programa pode ser considerado como o elemento desencadeador do processo de capacidade de absorção da instituição, visto que, conforme discutem Zahra e George (2002), mudanças tecnológicas e/ou alterações em políticas governamentais são vistos como ativadores de ordem externa da necessidade de aquisição de novos conhecimentos.

A investigação sobre a forma de assimilação, enquanto compreensão de conhecimento advindo de fora da organização (Jiménez-Barrionuevo, García-Morales, \& Molina, 2011), pautou-se em verificar que habilidades, experiências, formação educacional, além de conhecimentos prévios compatíveis e semelhantes, auxiliaram os membros organizacionais a entender as especificidades do Programa Paraná Digital. Por meio dos relatos, foi possível verificar que a assimilação ocorreu com base naquilo que as pessoas sabiam acerca do manuseio de recursos tecnológicos, visto que o estabelecimento de ensino já possuía um conjunto de equipamentos adquiridos com recursos da comunidade. "O sistema era diferente, mas nosso colégio tinha um laboratório com computadores comprados com o dinheiro arrecadado pela APMF (Associação de Pais, Mestres e Funcionários), e isso facilitou a instalação do novo laboratório" (E9).

Diferentemente do conhecimento que os indivíduos possuíam acerca do uso de computadores e sua aplicabilidade pedagógica, o Programa Paraná Digital trouxe uma proposta calcada no uso de softwares livres e conteúdos específicos disponibilizados no portal da Educação do Governo para que os educadores aprimorassem suas aulas. Isso exigiu que houvesse a combinação das experiências anteriores com novos conhecimentos, resultando, portanto, no que Jiménez-Barrionuevo et al. (2011) consideram como processo de transformação. Para que isso ocorresse, foram realizadas capacitações com professores e funcionários proporcionadas por agentes da Coordenação Regional de Tecnologia na Educação (CRTE), que se destina a prestar assistência e auxílio quanto ao uso dos laboratórios de informática e conteúdos do Paraná Digital. Tal coordenação está alocada em um setor do Núcleo Regional de Educação, que atua como órgão regulador das funções burocráticas dos colégios existentes na capital paranaense.

Além das capacitações, foram disponibilizados, em meio virtual, manuais voltados a explicar as melhores formas de utilização dos computadores e conteúdos que pudessem ser incorporados às práticas de docência. A maior dificuldade encontrada inicialmente se pautou no fato de que o novo sistema operacional, em plataforma Linux, diferia do sistema com o qual as pessoas estavam acostumadas, o Windows.

A observação, a pesquisa documental e as entrevistas revelam que a absorção de conhecimento na instituição ocorreu de maneira fluida e processual. Sinaliza, dessa forma, a existência de recursividade com o processo de aprendizagem organizacional, que, de acordo com a definição de Takahashi (2007), ocorre a partir de um fluxo que engloba a criação, utilização e institucionalização do conhecimento.

O processo inicial de criação, que é voltado a produzir conhecimento provisório e contestado em busca de conteúdo durável, por meio de debates e controvérsias dos membros organizacionais (Patriotta, 2003), é paralelo às dimensões de aquisição e assimilação verificadas na capacidade de absorção, nas quais as informações são tidas como de uso potencial, porém não efetivo, segundo ponderam Zahra e George (2002). Isso porque foi a partir da introdução do programa e da interpretação com base no que já sabiam acerca de tecnologia, que os educadores da instituição tentaram avaliar, em caráter primitivo, aquilo que seria necessário buscar conhecer, desenvolver e modificar na realização de suas atividades, conforme revela um dos entrevistados ao afirmar que "O Paraná Digital foi de fato um estopim a nível profissional..., obrigou todo mundo a correr atrás, a buscar aprender" (E6).

As análises e considerações inicialmente criadas se constituíram como primeiro passo de reflexão que prosseguiu para a fase na qual os membros organizacionais passaram a manipular e transformar o conhecimento. Isso caracteriza a etapa de utilização inerente ao processo de aprendizagem organizacional (Patriotta, 2003), e também a dimensão de transformação da capacidade de absorção, na qual os indivíduos expandem e modificam aquilo que sabem por meio do compartilhamento das novas 
informações, que se tornam úteis e aplicáveis na realidade organizacional (Jiménez-Barrionuevo et al., 2011).

A interação e partilha informacional entre os membros da organização se constituiu como elo necessário para viabilizar o processo de transformação do conhecimento, ou seja, possibilitou que ele fluísse da criação para a utilização. Houve, portanto, a mediação de mecanismos de integração social, que Zahra e George (2002) consideram imprescindíveis para que a capacidade de absorção passe do estágio potencial ao realizado. Tais mecanismos foram formalmente utilizados no colégio Professora Luiza Ross por meio de reuniões e capacitações, além de, informalmente, pela troca de experiências entre colegas de trabalho em momentos e espaços não previamente definidos, como horários de intervalos das aulas ou durante o lanche e descanso. Isso pôde ser verificado por meio da observação realizada e também pela fala dos entrevistados, como a pontuada a seguir: "aquilo que dá certo, a gente partilha, aquilo que dá errado, a gente partilha também, aquilo que às vezes pode dar certo pra um, pode não dar certo pra outro, mas existe sempre essa troca" (E3).

O trabalho conjunto, a troca de informações e a comunicação interna ocorrida no estabelecimento de ensino denota que houve integração social entre os membros organizacionais. Isso viabilizou a completude do processo de capacidade de absorção, pois gerou a transformação necessária para atingir a dimensão de exploração do conhecimento disseminado, ou seja, sua incorporação nas rotinas organizacionais (Zahra \& George, 2002). Essa dimensão final do processo de capacidade de absorção se encontra em consonância com a etapa de institucionalização que completa o fluxo da aprendizagem organizacional, delineado por Patriotta (2003), na qual o conhecimento transformado se torna aceito e inscrito nas práticas tidas como certas da organização, como exemplificado por um dos entrevistados: "O pessoal já está acostumado com o Paraná Digital.... porque virou parte do dia a dia” (E2).

O conhecimento desencadeado pela implantação do Programa Paraná Digital percorreu, portanto, todas as dimensões da capacidade de absorção (aquisição ou introdução, assimilação, transformação e exploração), em interface com as fases do fluxo de conhecimento (criação, utilização e institucionalização) da aprendizagem organizacional. Ou seja, ocorreu um processo recursivo iniciado pela introdução, assimilação e criação, que foi mediado por mecanismos de integração social que viabilizaram a transformação e utilização, para finalmente alcançar a exploração e institucionalização dos conteúdos. Verifica-se, portanto, além do papel da integração social, a ocorrência da recursividade delineada por autores como Van den Bosch et al. (1999), visto que, ao absorver conhecimentos relativos ao Programa Paraná Digital, a instituição parece ter vivenciado um processo de aprendizagem em nível organizacional. A experiência levou os docentes ao desenvolvimento de novas práticas, gerando maior entendimento quanto ao uso de tecnologias para a educação, ampliando a sua capacidade de absorver novos conteúdos correlacionados ao que foi aprendido.

A incorporação do Programa Paraná Digital nas atividades da escola como um todo pôde ser verificada por meio das entrevistas, dos documentos e das observações realizadas, assim como também pelas estatísticas, que revelam que o Colégio Professora Luiza Ross é um dos que mais fizeram uso dos computadores, na região de Curitiba, desde a implantação no local, ocorrida em 2007, até o fim do ano de 2013, somando um total de 113.794,635 horas (PRD Estatística, n. d.). Isso denota que os membros da instituição conseguiram absorver os conhecimentos inerentes ao Programa Paraná Digital (PRD) e vivenciar um processo de aprendizagem.

\section{O colégio Santo Agostinho}

Com um número aproximado de 800 alunos dispostos nos níveis de ensino fundamental, no período da manhã e tarde, e médio, no turno da noite, o Colégio Estadual Santo Agostinho está situado no bairro Boqueirão, Curitiba - Paraná, e possui um corpo funcional composto por cerca de 80 profissionais, alocados nos cargos de funcionários administrativos, serviços gerais, professores, pedagogos e diretores. O estabelecimento de ensino teve seu laboratório de informática, que é composto por 20 computadores em uma área de aproximadamente $56 \mathrm{~m}^{2}$, implantado no início do ano de 2007 por meio do Programa Paraná Digital. 
Ofertado devido ao desencadeamento da política governamental de uso de tecnologias para fins pedagógicos, a chegada do Programa Paraná Digital pode ser considerada como a obtenção de algo novo, constituindo-se como a etapa inicial da capacidade de absorção, visto que, para Hotho et al. (2012, p. 387), a aquisição pode ser "operacionalizada como a introdução de princípios de melhoria contínua".

A interpretação e entendimento acerca da novidade obtida, ou seja, o processo de assimilação de um novo conhecimento (Camisón \& Forés, 2010), pautou-se na experiência que os indivíduos possuíam acerca da utilização de computadores e de pesquisas na internet realizadas em suas casas ou demais localidades, visto que o estabelecimento de ensino não possuía, até então, um laboratório de informática. A aquisição, ou introdução do programa, juntamente com a assimilação inicial do mesmo, constituíramse como dimensões da capacidade de absorção paralelas à etapa de criação do conhecimento inerente ao fluxo de aprendizagem organizacional, visto que geraram a necessidade de refletir sobre aquilo que já se sabia e realizava, e sobre aquilo que seria necessário buscar mudar e compreender.

O fato de o sistema operacional implantado se embasar em um software livre, plataforma Linux, dificultou, inicialmente, a compreensão das pessoas, pois diferia daquilo que aquelas que faziam uso de recursos tecnológicos estavam adaptadas a utilizar. "Não havia ninguém que soubesse mexer com o Linux, porque em casa todo mundo usava Windows, então a gente teve que se virar e aprender a mexer pouco a pouco" (E3).

Com vistas a fazer com que as pessoas incorporassem o novo conhecimento em suas operações, combinando-o com o que já sabiam, por meio de um processo de transformação (Zahra \& George, 2002), foram efetuadas capacitações pela CRTE destinadas a fazer com que professores e funcionários aprendessem a utilizar os recursos proporcionados pelo Programa. Além disso, foram disponibilizados manuais na internet para orientar a utilização.

Apesar de terem ocorrido capacitações e disponibilização de manuais, os educadores não conseguiram aprender como utilizar o novo sistema e de que forma se valer de suas funcionalidades para melhorar suas práticas de ensino. Continuaram, assim, a realizar suas atividades da mesma forma que realizavam antes, não modificando, portanto, suas práticas. Desse modo, ainda que tenha havido reflexões e considerações iniciais criadas pela introdução do Programa Paraná Digital no Colégio Santo Agostinho, houve, por parte dos docentes, pouca transformação do conhecimento. Tal dimensão relevante e necessária para capacidade de absorção (Zahra \& George, 2002), conjuntamente com a etapa de utilização da aprendizagem organizacional, possibilitaria a agregação de novos saberes e a aplicação de mudanças e melhorias nas atividades organizacionais. Isso, no entanto, não foi eficazmente desenvolvido no estabelecimento de ensino.

Ao invés do laboratório de informática ser visualizado como local para preparar e ministrar aulas, a utilização passou a ser feita de maneira dissociada, ou seja, os computadores passaram a ser utilizados apenas para que os discentes realizassem pesquisas na internet em horário de contraturno, não havendo, desse modo, um acompanhamento e orientação de cunho pedagógico. "É difícil ver os professores levar os alunos no laboratório no horário de aula, eles usam mesmo fora do horário de aula" (E4).

A dificuldade encontrada em passar de um conhecimento introduzido, assimilado e criado para um patamar em que ele é transformado e utilizado, deve-se ao fato de que é necessário que haja mecanismos de integração social capazes de propiciar que isso ocorra, conforme discorrem Vega-Jurado et al. (2008). Essa mediação da integração social teve uma reduzida ênfase no Colégio Santo Agostinho, pois nos momentos de partilha formal de informações, ocorridas em reuniões, pouco foi discutido sobre o Paraná Digital. Tal situação também ocorreu informalmente, visto a baixa troca de experiências sobre o assunto entre os professores. "Eu acho que a verdade é que não tá sendo muito utilizado mesmo na escola, então a gente não troca experiência e informação porque não utiliza, daí você vai falar o quê? Eu acredito que seja isso" (E1).

Essa falta de comunicação e integração, ocorrida no colégio Santo Agostinho, também é pontuada como problemática no Projeto Político Pedagógico, no qual está descrito que "alguns profissionais que 
trabalham em dois turnos comentam que parecem estar trabalhando em escolas diferentes, a cada turno, devido à diferença na condução dos trabalhos" (Colégio Estadual Santo Agostinho, 2011, p. 17).

Sem muitos mecanismos de integração social que pudessem efetivamente viabilizar a transformação e utilização do conhecimento, tornou-se também improvável que se alcançasse a interface entre exploração e institucionalização, enquanto fases que completam o processo de capacidade de absorção e aprendizagem organizacional, respectivamente, e que se voltam à inserção efetiva de algo novo no cotidiano de uma organização (Jiménez-Barrionuevo et al., 2011; Patriotta, 2003). Sendo assim, o Programa Paraná Digital não se tornou aceito, explorado e incorporado no trabalho educacional da maioria dos docentes da instituição.

Como o conhecimento não foi efetivamente explorado e institucionalizado por não ter sido amplamente transformado e utilizado, devido à ausência eficaz de mecanismos de integração social capazes de difundi-lo pela organização, ele permaneceu restrito à etapa de introdução, assimilação e criação. Ou seja, os processos de capacidade de absorção e de aprendizagem organizacional não ocorreram completamente, demonstrando, dessa forma, a recursividade entre ambos, visto que a incompletude de um automaticamente implicou na incompletude do outro. O conhecimento permaneceu em um estágio potencial de absorção e não chegou ao pleno nível de absorvimento. Assim, não há indícios de que tenha ocorrido um processo de aprendizagem em nível organizacional no que se refere ao ciclo do conhecimento. $\mathrm{O}$ que talvez possa ter ocorrido seja uma aprendizagem individual de alguns docentes que tenham explorado o programa, algo que não foi possível averiguar no âmbito desta pesquisa.

Em suma, como reflexo da pouca discussão, integração e partilha de conhecimento, as propriedades do Programa Paraná Digital não têm sido amplamente exploradas no Colégio Santo Agostinho. Números estatísticos apontam o estabelecimento de ensino como um dos que efetuou menor utilização do programa dentre as escolas estaduais da região de Curitiba, tendo despendido 42.245,856 horas desde a implantação, em 2007, até o fim do ano de 2013 (PRD Estatística, n. d.). Tal fato ilustra que o aprendizado sobre a novidade introduzida não ocorreu de modo amplo entre os indivíduos da organização.

\section{Comparação entre os casos}

Tanto o colégio Professora Luiza Ross quanto o Colégio Santo Agostinho estão localizados no mesmo bairro, Boqueirão, e ofertam ensino na mesma modalidade e turnos a uma quantidade parecida de alunos, havendo uma diferença aproximada de 100 discentes entre uma escola e outra. Possuem número similar de funcionários distribuídos nas diferentes funções. Ambas as intuições tiveram o laboratório de informática do Programa Paraná Digital, com 20 computadores, implantado no início do ano de 2007. Estes dados, sintetizados na Tabela 2, permitiram a escolha das escolas para a condução do estudo de caso comparativo.

Tabela 2

\section{Comparação entre as Características Gerais das Duas Instituições Escolhidas no Estudo}

\begin{tabular}{lll}
\hline Características & Colégio Estadual Prof. ${ }^{a}$ Luiza Ross & Colégio Estadual Santo Agostinho \\
\hline Localização & Bairro Boqueirão - Curitiba / PR & Bairro Boqueirão - Curitiba / PR \\
Níveis de ensino ofertados & Fundamental e Médio & Fundamental e Médio \\
Período de funcionamento & Manhã, tarde e noite & Manhã, tarde e noite \\
Número de profissionais & Aproximadamente 80 & Aproximadamente 80 \\
Número de alunos & Cerca de 900 & Cerca de 800 \\
\hline
\end{tabular}


Tabela 2 (continuação)

\begin{tabular}{lll}
\hline Características & Colégio Estadual Prof. ${ }^{a}$ Luiza Ross & Colégio Estadual Santo Agostinho \\
\hline Número de computadores & 20 & 20 \\
$\begin{array}{l}\text { Tamanho do laboratório de } \\
\text { informática }\end{array}$ & $74,20 \mathrm{~m}^{2}$ & $56 \mathrm{~m}^{2}$ \\
$\begin{array}{l}\text { Ano de implantação do Programa } \\
\text { Paraná Digital }\end{array}$ & 2007 & 2007 \\
\hline
\end{tabular}

Nota. Fonte: Secretaria da Educação - Consulta Escola. (n.d.). Escolas do município de Curitiba. Recuperado em 14 de dezembro, 2013 de http://www.consultaescolas.pr.gov.br/consultaescolas/f/fcls/municipio/visao. Foram utilizadas, conjuntamente, informações obtidas junto aos dirigentes dos estabelecimentos de ensino.

A recursividade existente entre a capacidade de absorção e a aprendizagem organizacional pôde ser identificada em ambos os casos selecionados no que tange ao fluxo do conhecimento. O mesmo padrão de instalação dos recursos e os poucos conhecimentos prévios acerca do uso de tecnologias para fins educacionais, principalmente por estar baseado em plataforma Linux, gerou similaridades entre o Colégio Professora Luiza Ross e o Colégio Santo Agostinho em relação à introdução do Programa Paraná Digital e à assimilação do mesmo, calcada em experiências anteriores. Isso desencadeou, paralelamente, semelhantes processos de criação do conhecimento, pautados em reflexões e buscas por tentar visualizar as mudanças que seria preciso realizar para aprender a lidar com a novidade implementada.

A transformação do conhecimento foi a etapa em que o processo começou a tomar caminhos distintos em cada organização, gerando, assim, uma distinta utilização. Enquanto os professores do Colégio Professora Luiza Ross conseguiram utilizar as informações, transformando-as, os docentes do Colégio Santo Agostinho não visualizaram grandes possibilidades de aplicação em sua forma de trabalhar, pois não utilizaram os novos conteúdos para expandir aquilo que conheciam e para transformar seu modo de agir.

O diferencial do Colégio Professora Luiza Ross se deve ao fato de que houve preocupação em gerar integração social entre os membros organizacionais, valendo-se tanto da comunicação formal e sistematizada quanto do estabelecimento de redes informais de troca de informações e experiências. Tal fato gerou mecanismos que mediaram a absorção do conhecimento, pois fizeram com que ele fluísse pela organização e passasse de um estágio de capacidade de absorção potencial a outro de capacidade de absorção realizada (Zahra \& George, 2002). Aceitação e envolvimento na adoção de novos procedimentos, adaptação, integração e comunicação entre as pessoas, e compartilhamento informacional, considerados, por Hotho et al. (2012), como elementos viabilizadores da compreensão, aprendizado e utilização de novos conhecimentos, foram adotados no Colégio Professora Luiza Ross, em contraponto ao Colégio Santo Agostinho que não se valeu desses fatores interacionais para ampliar sua compreensão e promover o uso pedagógico do Programa Paraná Digital (PRD).

Sem uma integração social capaz de gerar transformação por parte dos professores, o Colégio Santo Agostinho não conseguiu partir para uma efetiva exploração dos novos recursos obtidos, não havendo, dessa forma, a institucionalização do conhecimento, que foi alcançada somente no Colégio Professora Luiza Ross, no qual os membros incorporaram o Programa Paraná Digital em suas rotinas, explorando-o cotidianamente e gerando um percentual de utilização 270 vezes maior quando comparado com o outro estabelecimento de ensino.

A comparação entre as instituições, que congrega a relação recursiva entre a capacidade de absorção e a aprendizagem organizacional quanto ao fluxo de conhecimento, mediada pelos mecanismos de integração social, é apresentada em forma de síntese na Figura 1. 


\begin{tabular}{l}
$\begin{array}{l}\text { Introdução e } \\
\text { Assimilação }\end{array}$ \\
\hline Criação
\end{tabular}

Mecanismos de Integração Social

- Difusão formal e informal do \begin{tabular}{|c|c|}
\hline L. R. & S.A. \\
\hline $\mathbf{S}$ & - \\
\hline
\end{tabular}

C.A. significa Capacidade de Absorção A.O. significa Aprendizagem Organizacional L.R. significa Colégio Estadual Professora Luiza Ross S.A. significa Colégio Estadual Santo Agostinho

Figura 1. Síntese de Comparação dos Processos Recursivos de Capacidade de Absorção e de Aprendizagem Organizacional, por meio dos Mecanismos de Integração Social, Ocorridos nos Casos Estudados

O símbolo de mais (+) denota que as etapas dos processos ocorreram com efetividade, o símbolo de menos (-) denota que as etapas dos processos não ocorreram ou ocorreram com pouca efetividade, e o símbolo formado por duas setas curvas (que formam um círculo aberto em suas extremidades) indica a existência de recursividade.

Cabe ressaltar que o conceito de aprendizagem organizacional nessa figura se refere à dimensão de fluxo do conhecimento. Embora tenha sido possível verificar indícios de que ela tenha ocorrido no Colégio Professora Luiza Ross e de que não tenha ocorrido no Colégio Santo Agostinho, ainda assim não é possível afirmar que a aprendizagem se deu em nível organizacional no primeiro. Uma análise complementar e aprofundada sobre a cultura organizacional e o impacto das mudanças nos valores organizacionais, junto a uma análise da profundidade das mudanças ocorridas, poderia revelar tal fenômeno. Porém, relevante aqui, para o propósito desta pesquisa, é evidenciar que há uma recursividade entre os dois conceitos na dimensão do conhecimento, uma vez que a existência das quatro etapas da capacidade de absorção implicou na existência das três fases do fluxo do conhecimento do processo de aprendizagem organizacional em um caso, ao mesmo tempo em que a incompletude de um implicou na incompletude do outro, no outro caso.

A Tabela 3 apresenta, de maneira comparativa, os principais aspectos inerentes e resultantes a cada uma das etapas dos processos de capacidade de absorção e de aprendizagem organizacional, expostos ao longo desta pesquisa, nas duas organizações analisadas. Ilustra, portanto, de forma condensada, as semelhanças e distinções existentes e que contribuíram para os resultados discutidos. 
Tabela 3

Comparação dos Aspectos Inerentes e Resultantes de Cada Etapa dos Processos de Capacidade de Absorção e de Aprendizagem Organizacional nas Duas Organizações Analisadas

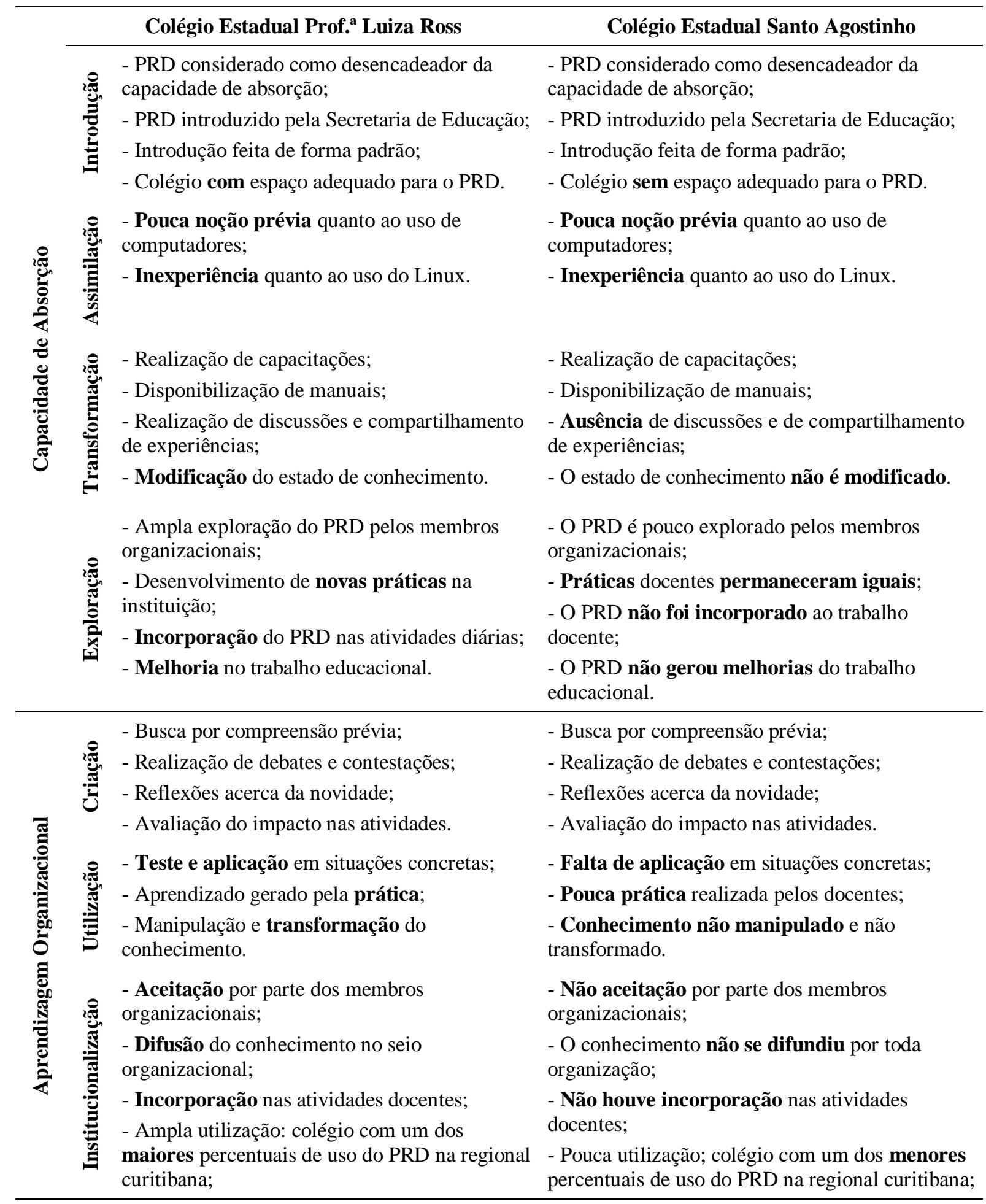

Nota. As informações sumarizadas na Tabela 3 foram obtidas por meio das pesquisas realizadas em cada uma das instituições de ensino, conforme descrito ao longo do texto. A sigla PRD significa Programa Paraná Digital. 


\section{Considerações Finais}

A capacidade de absorção de novos conhecimentos e a aprendizagem organizacional diferem entre as organizações, pois, ainda que a fonte seja a mesma, as características internas acabam por impactar o modo como algo novo é incorporado e utilizado (Camisón \& Forés, 2011). Isso pôde ser observado por meio do estudo de caso comparativo realizado.

Ao se analisar as dimensões que compõem a capacidade de absorção, juntamente com aspectos relativos à aprendizagem organizacional e mecanismos de integração social, puderam-se perceber semelhanças e diferenças entre as instituições educacionais quanto à implantação, compreensão, incorporação e uso do Programa Paraná Digital. As similaridades permaneceram no campo de obtenção e entendimento inicial dos propósitos do programa, como consequência da política governamental que introduziu essa novidade no ambiente escolar (dimensão potencial). Verificaram-se, no entanto, divergências quanto à forma de internalização e aplicação do conhecimento destinado a gerar melhorias nas atividades (dimensão realizada). Enquanto em um colégio houve um completo fluxo de conhecimento do processo de aprendizagem organizacional, que resultou na modificação da forma de realizar as atividades, no outro o fluxo ocorreu de forma incompleta, sem gerar mudanças nas rotinas e comportamentos que já estavam estabelecidos. Pôde-se perceber que esse resultado está atrelado à diferença de mecanismos de integração social existentes nas duas instituições. Cabe ressaltar que nem todo tipo de mudança implica em aprendizagem em nível organizacional, pois para tanto é preciso que haja o envolvimento de vários níveis (indivíduos, grupos e organização), na criação, utilização e institucionalização do conhecimento (Takahashi, 2007).

As distinções de integração social ocorridas em cada uma das organizações contribuíram para que elas chegassem a resultados diferentes. Ao se valer amplamente dos mecanismos de integração social, o Colégio Professora Luiza Ross vivenciou todas as dimensões da capacidade de absorção, bem como todas as fases do fluxo de conhecimento da aprendizagem organizacional, gerando um processo recursivo no qual a absorção gerou alguma forma de aprendizado, que ampliou a capacidade de absorver conhecimentos.

Essa recursividade ficou demonstrada, ainda, no caso do Colégio Santo Agostinho, embora de maneira diversa, visto que a reduzida integração social levou à incompletude do processo de capacidade de absorção que, como consequência recursiva, inviabilizou a fluidez completa do conhecimento, da criação à institucionalização (Patriotta, 2003), impossibilitando que o processo de aprendizagem ocorresse. $\mathrm{O}$ aspecto de fluidez processual do conhecimento se constitui, assim, como fator comum e inerente tanto à absorção quanto ao aprendizado, sendo responsável por viabilizar a relação recursiva entre eles. Tal conjuntura permitiu responder ao objetivo delineado, que se voltava a buscar compreender de que maneira se dá o processo recursivo de capacidade de absorção e de aprendizagem organizacional por meio de mecanismos de integração social, valendo-se do estudo de caso comparativo entre duas instituições de ensino público de Curitiba - Paraná.

Observa-se, a partir da visualização desses resultados, que os mecanismos de integração social desempenham papel essencial para viabilizar a aprendizagem e, consequente, o aumento da capacidade de absorção. Sugere-se, dessa forma, que novas pesquisas, abordando essa temática, sejam realizadas em outros ambientes organizacionais, levando a expandir o número de estudos empíricos que possibilitem melhor compreender a relação de recursividade dos processos desencadeados a partir da introdução de uma novidade no campo organizacional. Considera-se pertinente, ainda, desenvolver estudos voltados a delinear os principais elementos que podem configurar os mecanismos de integração social, buscando identificar o impacto gerado no fluxo de aprendizagem e absorção do conhecimento. 


\section{Referências}

Argyris, C., \& Schon, D. A. (1978). Organizational learning: a theory of action perspective. Workingham: Addison-Wesley.

Autio, R., Sapienza, H. J., \& Almeida, J. G. (2000). Effects of age at entry, knowledge intensity, and imitability on international growth. Academy of Management Journal, 43(5), 909-924. doi: $10.2307 / 1556419$

Bardin, L. (2010). Análise de conteúdo. Lisboa: Edições 70.

Barr, P. S., Stimpert, J. L., \& Huff, A. S. (1992). Cognitive change, strategic action, and organizational renewal. Strategic Management Journal, 13(S1), 15-36. doi: 10.1002/smj.4250131004

Camisón, C., \& Forés, B. (2010). Knowledge absorptive capacity: new insights for its conceptualization and measurement. Journal of Business Research, 63(7), 707-715. doi: 10.1016/j.jbusres.2009.04.022

Camisón, C., \& Forés, B. (2011). Knowledge creation and absorptive capacity: the effect of intra-district shared competences. Scandinavian Journal of Management, 27(1), 66-86. doi: 10.1016/j.scaman.2010.11.006

Chauvet, V. (2014). Absorptive capacity: scale development and implications for future research. Management International, 19(1), 113-130. doi: 10.7202/1028493ar

Cohen, W. M., \& Levinthal, D. A. (1990). Absorptive capacity: a new perspective on learning and innovation. Administrative Science Quartely, 35(1), 128-152. doi: 10.2307/2393553

Colégio Estadual Santo Agostinho. (2011). Projeto político pedagógico (Relatório interno/2011). Curitiba, PR, Brasil.

Dhanaraj, C., Lyles, M. A., Steensma, H. K., \& Tihanyi, L. (2004). Managing tacit and explicit knowledge transfer in IJVs: the role of relational embeddedness and the impact on performance. Journal of International Business Studies, 35(5), 428-442. doi: 10.1057/palgrave.jibs.8400098

Dong, J. Q., \& Yang, C.-H. (2015). Information technology and organizational learning in knowledge alliances and networks: evidence from U.S. pharmaceutical industry. Information \& Management, 52(1), 111-122. doi: 10.1016/j.im.2014.10.010

Dyer, J. H., \& Singh, H. (1998). The relational view: cooperative strategy and sources of interorganizational competitive advantage. Academy of Management Review, 23(4), 660-679. doi: 10.5465/AMR.1998.1255632

Fiol, C. M., \& Lyles, M. A. (1985). Organizational learning. The Academy of Management Review, 10(4), 803-813. doi: 10.5465/AMR.1985.4279103

Hotho, J. J., Becker-Ritterspach, F., \& Saka-Helmhout, A. (2012). Enriching absorptive capacity through social interaction. British Journal of Management, 23(3), 383-401. doi: 10.1111/j.14678551.2011.00749.x

Jansen, J. P., Van den Bosch, F. A. J., \& Volberda, H. W. (2005). Managing potencial and realized absorptive capacity: how do organizational antecedents matter. Academy of Management Journal, 48(6), 999-1015. doi:10.5465/AMJ.2005.19573106

Jiménez-Barrionuevo, M. M., García-Morales, V. J., \& Molina, L. M. (2011). Validation of an instrument to measure absorptive capacity. Technovation, 31(5/6), 190-202. doi: 10.1016/j.technovation.2010.12.002 
Kim, L. (1998). Crisis construction and organizational learning: capability building in catching-up at Hyundai Motor. Organization Science, 9(4), 506-521. doi: 10.1287/orsc.9.4.506

Lane, P. J., Koka, B. R., \& Pathak, S. (2006). The reification of absorptive capacity: a critical review and rejuvenation of the construct. Academy of Management Review, 31(4), 833-863. doi: 10.5465/AMR.2006.22527456

Lane, P. J., \& Lubatkin, M. (1998). Relative absorptive capacity and interorganizational learning. Strategic Management Journal, 19(5), 461-477. doi: 10.1002/(SICI)10970266(199805)19:5<461::AID-SMJ953>3.0.CO;2-L

Leal-Rodríguez, A. L., Ariza-Montes, J. A., Roldán, J. L., \& Leal-Millán, A. G. (2014). Absorptive capacity, innovation and cultural barriers: a conditional mediation model. Journal of Business Research, 67(5), 763-768. doi: 10.1016/j.jbusres.2013.11.041

Liao, J., Welsch, H. P., \& Stoica, M. (2003). Organizational absorptive capacity and responsiveness: an empirical investigation of growth-oriented SMEs. Entrepreneurship Theory and Practice, 28(1), 63-85. doi: 10.1111/1540-8520.00032

Lichtenthaler, U. (2009). Absorptive capacity, environmental turbulence, and the complementarity of organizational learning processes. Academy of Management Journal, 52(4), 822-846. doi: 10.5465/AMJ.2009.43670902

Mowery, D. C., \& Oxley, J. E. (1995). Inward technology transfer and competitiveness: the role of national innovation systems. Cambridge Journal of Economics, 19(1), 67-93.

Neuman, W. L. (1999). Social research methods: qualitative and quantitative approaches. Boston: Allyn and Bacon.

Patriotta, G. (2003). Organizational knowledge in the making: how firms create, use, and institutionalize knowledge. United States: Oxford University Press.

Patterson, W., \& Ambrosini, V. (2015). Configuring absorptive capacity as a key for research intensive firms. Technovation, (36/37), 77-89. doi: 10.1016/j.technovation.2014.10.003

PRD Estatística - Análise de Uso de Computadores nas Escolas. (n.d.). Relatórios por período. $\begin{array}{llllll}\text { Recuperado em } & 27 & \text { de } & \text { dezembro, } & 2013 & \text { de }\end{array}$ http://www.prdestatistica.seed.pr.gov.br/pentaho/jsp/PrdDashboardData.jsp?dataInicial=01/01/2 $007 \&$ dataFinal $=27 / 12 / 2013 \&$ reg=Curitiba\#aesc

Schildt, H., Keil, T., \& Maula, M. (2012). The temporal effects of relative and firm-level absorptive capacity on interorganizational learning. Strategic Management Journal, 33(10), 1154-1173. doi: $10.1002 /$ smj. 1963

Secretaria da Educação - Consulta Escola. (n.d.). Escolas do município de Curitiba. Recuperado em 14 de dezembro, 2013 de http://www.consultaescolas.pr.gov.br/consultaescolas/f/fcls/municipio/visao. Foram utilizadas, conjuntamente, informações obtidas junto aos dirigentes dos estabelecimentos de ensino.

Secretaria de Estado da Educação. (2010). Paraná digital: tecnologias de informação e comunicação nas escolas públicas paranaenses (Relatório final/2010). Curitiba, PR, Brasil. Recuperado de http://www.gestaoescolar.diaadia.pr.gov.br/arquivos/File/pdf/parana_digital.pdf

Sun, P. Y. T., \& Anderson, M. H. (2010). An examination of the relationship between absorptive capacity and organizational learning, and a proposed integration. International Journal of Management Reviews, 12(2), 130-150. doi: 10.1111/j.1468-2370.2008.00256.x 
Takahashi, A. R. W. (2007). Descortinando os processos da aprendizagem organizacional no desenvolvimento de competências em instituições de ensino (Tese de doutorado). Universidade de São Paulo, São Paulo, SP, Brasil.

Todorova, G., \& Durisin, B. (2007). Absorptive capacity: valuing a reconceptualization. Academy of Management Review, 32(3), 774-786. doi: 10.5465/AMR.2007.25275513

Tsai, W. (2001). Knowledge transfer in intraorganizational networks: effects of network position and absorptive capacity on business unit innovation and performance. Academy of Management Journal, 44(5), 996-1004. doi: 10.2307/3069443

Van den Bosch, F. A. J., Volberda, H. W., \& Boer, M. de (1999). Coevolution of firm absorptive capacity and knowledge environment: organizational forms and combinative capabilities. Organization Science, 10(5), 551-568. doi: 10.1287/orsc.10.5.551

Vega-Jurado, J., Gutiérrez-Gracia, A., \& Fernández-de-Lucio, I. (2008). Analyzing the determinants of firm's absorptive capacity: beyond R\&D. $R \& D$ Management, 38(4), 392-405. doi: 10.1111/j.1467-9310.2008.00525.x

Versiani, A. F., \& Fischer, A. L. (2008). A aprendizagem organizacional como um campo específico de conhecimento no cenário dos estudos organizacionais. Revista E\&G Economia e Gestão, 8(18), $10-31$.

Volberda, H. W., Foss, N. J., \& Lyles, M. A. (2010). PERSPECTIVE - Absorbing the concept of absorptive capacity: how to realize its potential in the organization field. Organization Science, 21(4), 931-951. doi: 10.1287/orsc. 1090.0503

Yin, R. K. (2010). Estudo de caso: planejamento e métodos (4a ed.). Porto Alegre: Bookman.

Zahra, S. A., \& George, G. (2002). Absorptive capacity: a review, reconceptualization, and extension. Academy of Management Review, 27(2), 185-203. doi: 10.5465/AMR.2002.6587995

\section{Dados dos Autores}

Florindo Rhaoni Picoli

Av. Prof. Lothário Meissner, 632, Jardim Botânico, 80210-170, Curitiba, PR, Brasil. E-mail: rhaonipicolli@gmail.com

Adriana Takahashi

Av. Prof. Lothário Meissner, 632, Jardim Botânico, 80210-170, Curitiba, PR, Brasil. E-mail: adrianarwt@terra.com.br 